\title{
Surfactant-assisted aqueous extraction of palm-pressed mesocarp fiber residual oil with Tween 80 solution
}

\begin{abstract}
The potential of Tween 80, a commercial food-grade non-ionic surfactant, was evaluated for the extraction of residual oil from palm-pressed mesocarp fibre (PPMF). Results show that the critical micelle concentration (CMC) was achieved at $0.05 \mathrm{wt} \%$ surfactant with an interfacial tension (IFT) of $0.51 \mathrm{mN} / \mathrm{m}$. The extraction yield however depends not only on the IFT but also on the viscosity and the solid to liquid ratio of the extracting solution. The highest percentage of oil extraction (47.36\%) was obtained at $1 \mathrm{wt} \%$ Tween 80 with $6 \%$ $\mathrm{NaCl}$, temperature of $60^{\circ} \mathrm{C}$ and a solid-liquid ratio of $8 \mathrm{~g}$ PPMF: $200 \mathrm{~g}$ solution.
\end{abstract}

Keyword: Aqueous extraction process; Food-grade surfactant; Interfacial tension; Palmpressed mesocarp fibre; Tween 80 